\title{
PENGARUH EFEKTIVITAS FUNGSI AUDIT INTERNAL TERHADAP PENGUNGKAPAN KELEMAHAN PENGENDALIAN INTERNAL
}

(Studi pada BUMN yang berkantor pusat di Kota Bandung)

\author{
Oleh: \\ Rozmita Dewi Yuniarti Rozali \\ (Program Studi Akuntansi FPEB Universitas Pendidikan Indonesia) \\ Rizal Alfian \\ (Program Studi Akuntansi FPEB Universitas Pendidikan Indonesia)
}

\begin{abstract}
This research purpose to know how influence the effectiveness of the internal audit function on the disclosure weaknesses control in BUMN headoffice in Bandung. The research method used is associative method. The population this research are internal auditors who are in all BUMN headoffice in Bandung, whereas for sampling using sample iteration. This research using primary data wich collected from questionnaires. This research using a simple statictical correlation Spearman Rank in analyzing the data. Based on the calculation of correlation analysis with the help of software SPSS 20.0 for Windows, questionnaire distributed to 55 internal auditors at 5 BUMN headoffice in Bandung showed that the effectiveness of the internal audit function has positive influence on the disclosure of internal control weaknesses. Percentage influence the effectiveness of the internal audit function to the disclosure of internal control weaknesses were $33.5 \%$ and $66.5 \%$ influenced by other factors not examined in this research.
\end{abstract}

Keywords: effectiveness of the internal audit function, disclosure weakness internal control

\section{Pendahuluan}

Selama ini banyak artikel dan berita mengenai skandal keuangan yang terjadi di Enron, WorldCom, dan beberapa perusahaan lainnya. Banyak pihak mengalami kecemasan bahwa skandal-skandal tersebut akan membahayakan kelangsungan ekonomi di Amerika Serikat. Oleh karenanya upaya yang dilakukan yaitu melalui Kongres Amerika sehingga resesi keuangan yang terjadi di tahun 1929 tidak terjadi lagi. Selanjutnya kongres ini menetapkan undang-undang keuangan yang kemudian dikenal dengan Sarbanes-Oxley Act 2002.

Salah satu aspek penting dari SOX adalah terdapat dua bagian khusus berfokus pada isu-isu pengendalian internal terkait dengan pelaporan keuangan. Menurut Section 302, manajemen diwajibkan untuk mengungkapkan semua kelemahan material dalam pengendalian internal, pada saat mereka mengesahkanlaporan keuangan baik secara periodik, tahunan dan triwulanan. Menurut Section 404, perusahaan diwajibkan untuk menilai efektivitas struktur pengendalian internal dan prosedur dalam pelaporan keuangan dan 
mengungkapkan informasi tersebut dalam laporan tahunannya. ( Y. Zang, et al :2007).

Di Indonesia, bagi Badan Usaha Milik Negara (BUMN) keharusan penyelenggaraan pengendalian internal berbasis framework COSO tersebut tertuang dalam pasal 26 Peraturan Kementerian Badan Usaha Milik Negara (BUMN) No.PER - 01 /MBU/2011 tanggal 1 Agustus 2011 mengenai Penerapan Good Corporate Governance (GCG) pada BUMN, yang diperjelas lebih lanjut dengan keputusan Sekretaris Menteri BUMN nomor SK- 16 /S.MBU/2012 pada tanggal 6 Juni 2012 tentang Indikator/Parameter Penilaian dan Evaluasi atas GCG pada BUMN. Peraturan ini memang hanya mengikat bagi perusahaan pelat merah saja. Namun, regulasi bagi BUMN tersebut dapat menjadi salah satu acuan praktik audit internal yang baik (best practice) bagi korporasi lain di Indonesia.

Di Indonesia, pengungkapan kelemahan pengendalian internal belum banyak ditemui karena masih bersifat voluntary (sukarela). Namun apabila sebuah perusahaan telah terdaftar di bursa efek Amerika Serikat, maka perusahaan tersebut wajib melakukan pengungkapan kelemahan pengendalian internal karena terikat oleh peraturan dari SOX. Di Indonesia sendiri ada dua perusahaan yang telah terdaftar di New York Stock Exchage (NYSE) yaitu PT Telkom Indonesia Tbk.

Berdasarkan laporan tahunan PT Telkom Indonesia, Tbk tahun 2009 menyatakan bahwa proyeksi atas evaluasi efektivitas pada masa mendatang mengandung risiko bahwa pengendalian mungkin menjadi tidak memadai karena perubahan kondisi, atau karena tingkat kepatuhan terhadap kebijakan atau prosedur mungkin menurun. Manajemen Perusahaan telah melakukan penilaian atas efektivitas pengendalian internal atas pelaporan keuangan Perusahaan pada tanggal 31 Desember 2009. Berdasarkan hasil penilaian ini, manajemen menyimpulkan bahwa pada tanggal 31 Desember 2009, pengendalian internal atas pelaporan keuangan Perusahaan telah efektif.

Evaluasi terhadap efektivitas pengendalian dan prosedur pengungkapan Perusahaan sebagaimana dipersyaratkan dalam Pedoman pengungkapan Informasi kepada Publik sesuai SOA section 302 diatur. Berdasarkan evaluasi ini, Direktur Utama dan Direktur Keuangan Perusahaan menyimpulkan bahwa, pada tanggal 31 Desember 2009, pengendalian dan prosedur pengungkapan Perusahaan adalah efektif. Pengendalian dan prosedur PT Telkom Indonesia, Tbk telah melakukan penilaian atas efektivitas pengendalian internal atas pelaporan keuangan Perusahaan dengan menggunakan kriteria dalam InternalControlIntegratedFramework.

Pengungkapan Perusahaan termasuk pengendalian dan prosedur yang dirancang untuk memastikan bahwa informasi yang dipersyaratkan untuk diungkapkan di dalam laporan yang disampaikan atau diajukan berdasarkan Exchange Act telah dicatat, diproses, dirangkum dan dilaporkan dalam jangka waktu yang telah ditetapkan sesuai ketentuan dan format SEC, dan bahwa informasi tersebut dikumpulkan dan disampaikan kepada manajemen Perusahaan, termasuk Direktur Utama dan Direktur Keuangan, sebagaimana layaknya, untuk memungkinkan pengambilan keputusan yang tepat 
Dengan fakta yang ditemukan di atas terlihat bahwa Pelaksanaan audit internal yang dimiliki oleh perusahaan telah berjalan dengan efektif dan pengendalian internal yang dilakukan pun cukup maksimal. BUMN harus melakukan pengendalian internal terhadap seluruh kegiatannya terutama yang menyangkut keuangan yang dimiliki, karena pengendalian internal merupakan salah satu indikator yang dilihat oleh auditor eksternal untuk dijadikan acuan bagi laporan hasil audit.

Auditor internal memiliki peran penting didalam suatu perusahaan, karena peran auditor internal berpengaruh terhadap kemungkinan terjadinya kesalahan, ketidakakuratan ataupun kecurangan dalam perusahaan. Menurut Albrecht and Albrecht (2004) struktur pengendalian yang efektif adalah langkah yang paling penting untuk menghilangkan atau mengurangi kesempatan untuk melakukan penipuan. Fungsi audit internallebih mampu dan lebih mungkin untuk mendeteksi dan memperbaiki masalah pengendalian yang kecil sebelum mereka menjadi cukup berat sehingga dianggap kelemahan material.

Hubungan ini adalah logis dan secara sederhana berarti bahwa jika kondisi pengendalian internal dan fungsi audit internal berjalan dengan baik maka laporan keuangan kecil kemungkinannya mengandung salah saji yang material, maka auditor dapat melakukan pengujian subtantif yang kurang mendalam ketimbang jika laporan keuangan mengandung salah saji yang material. Dengan kata lain auditor dapat mengurangi jumlah bukti yang dikumpulkan.

Pengungkapan kelemahan pengendalian internal terhadap perkembangan bisnis di Indonesia dibutuhkan untuk mengikuti perkembangan yang signifikan terutama pada sektor ekonomi. Saat ini perusahaan-perusahaan baik sektor publik maupun swasta menghadapi tantangan yang cukup berat, mulai dari perusahaan pesaing hingga praktik korupsi, kolusi, dan nepotisme (KKN), maka diperlukan tata kelola yang baik untuk keberlangsungan perusahaan. Terkait dengan tata kelola perusahaan yang baik (good corporategovernance), akibat adanya cara sumber daya diinvestasikan dan dikeloladalam dunia bisnis modern, sistem tata kelola perusahaan diperlukan (Messier et al. 2006). Perusahaan membentuk audit internal untuk pengawasan danmeningkatkan tata kelola yang baik pada perusahaan.

Berdasarkan latar belakang dan identifikasi masalah berdasarkan fenomena yang ada, maka pada penelitian penulis ini dirumuskan masalah bagaimana pengaruh efektivitas fungsi audit internal terhadap pengungkapan kelemahan pengendalian internal pada BUMN yang berkantor pusat di Kota Bandung. Dan tujuan penelitian ini adalah untuk mengetahui bagaimana pengaruh efektivitas fungsi audit internal terhadap pengungkapan kelemahan pengendalian internal pada BUMN yang berkantor pusat di Kota Bandung.

\section{Kajian Pustaka}

Definisi audit internal terus berkembang. Audit internal yang modern tidak lagi terbatas fungsinya dalam bidang pemeriksaan finansial, tetapi sudah meluaske bidang lain seperti manajemen audit, audit lingkungan hidup, sosial audit, auditinvestigasi, compliance audit.Menurut Hiro Tugiman (2006:11)audit internaladalah suatu fungsi penilaian yang independen dalam suatu organisasi untuk menguji dan mengevaluasi kegiatan organisasi yang dilaksanakan. Audit 
internal menurut The IIA Research Foundation (2011:2) yang dijelaskan dalam (IPPF) adalah:"Internal auditing is an independent, objective assurance and consulting activity designed to add value and improve an organization's operations. It helps an organization accomplish its objectives by bringing a systematic, disciplined approach to evaluate and improve the effectiveness of risk management, control, and governance processes." Definisi tersebut menyatakan bahwa audit internal merupakan aktivitas independen yang memberikan jaminan objektif dan konsultasi yang dirancang untuk memberi nilai tambah dan meningkatkan operasi organisasi. Aktifitas ini membantu organisasi mencapai tujuannya dengan membawa pendekatan yang sistematis dan disiplin untuk mengevaluasi dan meningkatkan efektifitas manajemen risiko, pengendalian, dan proses tata kelola. Pada Performance Standards 2100-Nature of Work tahun 2004 dijelaskan bahwa:"The internal audit activity should evaluate and contribute to the improvement of risk management, control, and governance processes using a systematic and disciplined approach."Aktivitas audit internal harus mengevaluasi dan memberikan kontribusi pada perbaikan manajemen risiko, pengendalian, dan proses tata kelola dengan menggunakan pendekatan sistematis dan disiplin. Kegiatan audit internal harus membantu organisasi dengan mengidentifikasi dan mengevaluasi eksposur signifikan untuk risiko dan memberikan kontribusi bagi perbaikan sistem manajemen risiko dan pengendalian. Konsorsium Organisasi Profesi Auditor Internal dalam Standar Profesi Audit Internal (SPAI, 2004:9) mendefinisikan audit internal adalah kegiatan assurance dan konsultasi yang independen dan obyektif, yang dirancang untuk memberikan nilai tambah dan meningkatkan kegiatan operasi organisasi.

Perusahaan merespon perubahan definsi audit internal sebagaimana yang telah dilakukan IIA (2004), mengeluarkan aturan mengenai audit internal dan hubungan pengawas dengan auditor pada perusahaan. Adapun beberapa hal yang menjadi perhatian mengenai audit internal didalam aturan yang dikeluarkan oleh IIA (2004) tersebut adalah sebagai berikut : Functioning of internal audit mencakup: (1) Working methods and types of audit; (2) Risk Focus and audit plan; (3) Procedures; (4) Management of internal audit department.Dari pengertian diatas dapat disimpulkan bahwa konsep fungsi audit internal merupakan elemen-elemen organisasi yang terintegrasi, penting dan tak tergantikan, pemenuhan standar professional mempunyai kontribusi yang sangat penting terhadap nilai tambah fungsi audit internal. Oleh karena itu, pemenuhan standar merupakan indikator fungsi audit internal.

Pengertian efektivitas yaitu keberhasilan (KBBI, 2001), atau ukuran berhasil tidaknya suatu organisasi mencapai tujuannya (Mardiasmo, 2002:134). Maka efektivitas fungsi audit internal dapat diartikan sebagai keberhasilan fungsi audit internal dalam melaksanakan tugas dan tanggung jawabnya kepada auditee sebagai pengguna jasa mereka sesuai dengan standar yang berlaku.Berbagai dimensi yang digunakan untuk mengukur variabel efektivitas fungsi audit internal tersebut merupakan penjabaran dari Standar Profesi Audit Internal (IIA, 2004). Sehingga hasil penelitian deskripsi variabel fungsi audit internal ini mendukung teori, bahwa pertimbangan tingkat pemenuhan standar merupakan salah satu factor yang mempengaruhi kinerja fungsi audit internal dan mempunyai 
kontribusi yang sangat penting terhadap nilai tambah fungsi ini untuk berfungsi secara efektif.

Menurut Alvin A. Arens, et al (2004:432) mengatakan bahwa "Suatu kelemahan pengendalian internal adalah pengendalian yang ada kurang memadai, yang mengakibatnya meningkatnya risiko dari salah saji dalam laporankeuangan. Jika menurut penilaian auditor, pengendalian itu tidak cukupuntuk memenuhi salah satu dari sasaran hasil audit yang terkait dengantransaksi, harapan dari salah saji demikian untuk terjadi akanmeningkat." Pendekatan empat langkah untuk mengidentifikasikan kelemahan pengendalian internal meliputi (1) Mengidentifikasikan pengendalian yang ada; (2) Mengidentifikasikan ketidakhadiran pengendalian kunci; (3) Menentukan salah saji material potensial yang bisa dihasilkan; (4) Mempertimbangkan kemungkinan pengendalian kompensasi.

Menurut Albrecht and Albrecht 2004 (dalam Lin, et al., 2011:291).Diketahui bahwa struktur pengendalian yang efektif adalah langkah yang paling penting untuk menghilangkan atau mengurangi kesempatan untuk melakukan penipuan. Fungsi audit internal lebih mampu dan lebih mungkin untuk mendeteksi dan memperbaiki masalah pengendalian yang kecil sebelum mereka menjadi cukup berat sehingga dianggap kelemahan material.

\section{Metode Penelitian}

Objek penelitian yang berkaitan dengan penelitian ini adalah efektivitas fungsi audit internal dan pengungkapan kelemahan pengendalian internal. Penelitian ini akan dilakukan pada BUMN yang berkantor pusat di Kota Bandung. Dengan menggunakan objek tersebut, peneliti ingin menganalisa bagaimana pengaruhefektivitas fungsi audit internal terhadappengungakapan kelemahan pengendalian internal . Penelitian ini dirancang dengan metode penelitian asosiatif dengan pendekatan kuantitatif. Dalam penelitian ini terdapat dua variabel efektivitas fungsi audit internal dan pengungkapan kelemahan pengendalian internal.

Populasi dalam penelitian ini adalah Badan Usaha Milik Negara yang berkantor pusat di Kota Bandung.Teknik sampling yang digunakan dalam penelitian ini adalah stratified probability random samplingdengan metode iterasi.Karena hasil iterasi bebebrapa tahap dan menghasilkan ukuran sampel minimal yang konsisten maka ditentukan ukuran sampel adalah sekitar 39, maka untuk kebutuhan sampel minimal yang representative diambil menjadi 55 responden.Dari ukuran sampel minimal 55, maka untuk pendistribusian pengambilan dari BUMN maka ditentukan BUMN yang secara random terpilih menjadi unit sampel penelitian.

Responden untuk Efektivitas Fungsi Audit Internal yaitu Staff Satuan Pengawasan Intern (SPI) sebagai auditor internal yang mengaudit Perusahaan tersebut yang penulis jadikan sampel, sedangkan untuk Pengungkapan Kelemahan Pengendalian Internal, penulis berikan kepada Staff Satuan Pengawasan Intern (SPI) sebagai auditor internal yang mengetahui bagaimana Pengungkapan Kelemahan Pengendalian Internal dihasilkan oleh auditor intern tersebut.Responden dalam penelitian ini adalah Auditor Internal pada 5 BUMN yang berpusat di Kota Bandung dikarenakan 4 BUMN yaitu PT. LEN Industri 
(Persero) dan PT. Pos Indonesia, (Persero), PT Perkebunan Nusantara (Persero) dan PT Dirgantara Indonesia (Persero) tidak bersedia untuk dijadikan sampel penelitian.Dalam penelitian ini penulis menggunakan data primer, dilakukan dengan berbagai cara yaitu obeservasi (pengamatan), wawancara terhadap narasumber, ataupun memberikan sejumlah daftar pertanyaan kepada responden (kuesioner) serta mengumpulkan data berupa dokumen ataupun catatan yang dibutuhkan.Penelitian ini dilakukan dengan menyebarkan kuesioner kepada responden untuk diisi secara langsung.

Pengujian validitas untuk instrument yang digunakan untuk mengukur sikap, pendapat, dan persepsi cukup memenuhi validitas kontruksi. Untuk mengukur validitas konstruk yaitu dengan mencari korelasi antara masing-masing pernyataan dengan skor total menggunakan rumus teknik korelasiSpearman Rank.

$$
\begin{aligned}
& \multicolumn{6}{c}{6 \sum d i^{2}} \\
r_{s} & =1-\frac{i=1}{n^{3}-n} \\
\mathrm{rs} & =\text { Koefisien korelasi } \\
\mathrm{di} & =\mathrm{Xi}-\text { Yi (selisih rangking) } \\
\mathrm{n} & =\text { Jumlah Responden }
\end{aligned}
$$

Bila korelasi tiap faktor tersebut positif dan besarnya 0,3 keatas maka faktor tersebut merupakan construct yang kuat(Sugiyono, 2010:115).Apabila alat ukur telah dinyatakan valid, maka selanjutnya alat ukur tersebut harus dilakukan uji reliabilitasnya. Pada penelitian ini, penulis menggunakan teknik dari Cronbach yang digunakan untuk mencari reliabilitas instrumen yang skornya bukan 1 dan 0 . Berikut rumus yang digunakan:

$$
r_{11}=\left(\frac{k}{k-1}\right)\left(\frac{1-\sum \sigma_{b}^{2}}{\sigma_{t}^{2}}\right)
$$

Sumber: Suharsimi Arikunto (2010:239)

Keterangan:

$\mathrm{r}_{11} \quad=$ reliabilitas instrumen

$\mathrm{k} \quad=$ banyaknya butir pertanyaan atau banyaknya soal

$\sum \sigma_{b}^{2}=$ jumlah varians butir

$\sigma_{t}^{2} \quad=$ varians total

Untuk menguji hipotesis yang diajukan yaitu "Efektivitas Fungsi Audit Internal berpengaruh terhadap Pengungkapan Kelemahan Pengendalian Internal", penulis menggunakan tes statistik dan perhitungan nilai tes statistik. Skala yang digunakan untuk mengukur kedua variabel penelitian adalah menggunakan skala ordinal dan pengujian ini dilakukan untuk mengetahui ada atau tidaknya pengaruh antara kedua variabel yang akan diteliti. Kriteria penerimaan dan penolakan hipotesis juga dapat menggunakan hasil dari pengujian Korelasi Spearman Rank dengan menggunakan Software SPSS 20.0 for Windows dengan melihat nilai signifikasinya sebagai berikut :

$H_{0}$ ditolak apabila nilai Sig. $<0,01$ Maka Tidak ada korelasi yang signifikan

$H_{a}$ diterima apabila nilai Sig. $>0,01$ Maka ada korelasi yang signifikan

Penelitian ini berkaitan dengan ada tidaknya pengaruh antara variabel $\mathrm{X}$ dengan variabel Y. Dalam penelitian ini hipotesis nol $H_{0}$ dan hipotesis alternatif $H_{a}$ dinyatakan sebagai berikut: 
$H_{0}: \rho=0$, Efektivitas Fungsi Audit Internal tidak berpengaruh terhadap

Pengungkapan Kelemahan Pengendalian Internal pada BUMN yang Berpusat di Kota Bandung.

$H_{a}: \rho \neq 0$, Efektivitas Fungsi Audit Internal berpengaruh terhadap

Pengungkapan Kelemahan Pengendalian Internal pada BUMN yang Berpusat di Kota Bandung.

Hipotesis yang diajukan akan diuji dengan menggunakan analisis korelasi rank spearman dengan rumus sebagai berikut :

$$
\begin{aligned}
& 6 \sum d i^{2} \\
{ }^{r} s & =1-\frac{i=1}{n^{3}-n} \\
\mathrm{rs} & =\text { Koefisien korelasi } \\
\mathrm{di} & =\mathrm{Xi}-\mathrm{Yi} \text { (selisih rangking) } \\
\mathrm{n} & =\text { Jumlah Responden }
\end{aligned}
$$

Hasil dari perhitungan koefisien tersebut dapat memberikan interprestasi terhadap kuatnya pengaruh tersebut, maka digunakan pedoman seperti yang dijelaskan oleh Sugiyono dalam bukunya "Metode Penelitian Bisnis" (2010 : 183) yang terdapat pada tabel berikut :

Pedoman untuk memberikan Interpretasi Koefisien Korelasi

\begin{tabular}{|l|l|}
\hline Interval Koefisien & Tingkat Hubungan \\
\hline $0,00-0,199$ & Sangat Rendah \\
$0,20-0,399$ & Rendah \\
$0,40-0,599$ & Sedang \\
$0,60-0,799$ & Kuat \\
$0,80-1,000$ & Sangat Kuat \\
\hline
\end{tabular}

Sumber : Sugiyono(2010)

Sedangkan untuk mengetahui seberapa besar pengaruh antara variabel $\mathrm{X}$ dengan Y maka penulis menggunakan rumus koefisien determinasi dengan memasukkan nilai dari

$$
\text { Kd }=\operatorname{rs~} \times 100 \%
$$

\section{Hasil dan Pembahasan}

Deskripsi Data Variabel X Secara Keseluruhan

Tabel 1

Rekapitulasi Persentase Rata-rata Jawaban Untuk Variabel X

\begin{tabular}{|c|l|c|c|}
\hline No & \multicolumn{1}{|c|}{ Efektivitas Fungsi Audit Internal } & $\begin{array}{c}\text { Persentase } \\
\text { Rata-rata } \\
(\boldsymbol{\%})\end{array}$ & Kategori \\
\hline 1 & Lingkup Tugas Audit Internal & 87 & Sangat Baik \\
\hline 2 & Karakteristik Fungsi Audit Internal & 88 & Sangat Baik \\
\hline 3 & Pelaksanaan Fungsi Audit Internal & 90 & Sangat Baik \\
\hline 4 & Manajemen Bagian Audit & 89 & Sangat Baik \\
\hline \multicolumn{2}{|c|}{ Jumlah } & 354 & \multirow{2}{*}{ Sangat Baik } \\
\cline { 1 - 2 } & Rata-rata & 88,5 & \\
\cline { 1 - 2 }
\end{tabular}

Sumber : Hasil Data Primer yang Telah Diolah 
Efektivitas fungsi audit internal termasuk dalam kategori sangat baik, menunjukan bahwa BUMN yang berkantor pusat di Kota Bandung, perlu diperhatikan pula unsur-unsur yang mendukung dalam pelaksanaan fungsi audit internal, seperti manajemen bagian audit yang kualitasnya perlu ditingkatkan agar terjaga konsistensi dalam menjalankan fungsi audit internal. Sehingga dalam melakukan aktivitas pengawasan yang dilakukan secara berkesinambungan dapat mendorong terciptanya iklim kerja yang efisien.

\section{Deskripsi Data Variabel Y Secara Keseluruhan}

Tabel 2

Rekapitulasi Persentase Rata-rata Jawaban Untuk Variabel Y

\begin{tabular}{|c|l|c|c|}
\hline No & Pengungkapan Kelemahan Pengendalian Internal & $\begin{array}{c}\text { Persentase } \\
\text { Rata-rata } \\
(\boldsymbol{\%})\end{array}$ & Kategori \\
\hline 1 & Mengidentifikasi pengendalian yang ada & 88 & Sangat Baik \\
\hline 2 & Mengidentifikasi ketidakhadiran pengendali kunci & 83 & Baik \\
\hline 3 & $\begin{array}{l}\text { Menetukan salah saji material potensial yang } \\
\text { dihasilkan }\end{array}$ & 87 & Sangat Baik \\
\hline 4 & $\begin{array}{l}\text { Mempertimbangkan kemungkinan pengendalian } \\
\text { kompensasi }\end{array}$ & 81 & Baik \\
\hline \multicolumn{2}{|c|}{ Jumlah } & 339 & Sangat Baik \\
\hline \multicolumn{2}{|c|}{ Rata-rata } \\
\hline
\end{tabular}

Sumber : Hasil Penelitian Data Diolah

Pengungkapan kelemahan pengendalian internal termasuk dalam kategori sangat baik, menunjukan bahwa BUMN yang berkantor pusat di Kota Bandung, pada umumnya telah mampu mengungkapkan kelemahan pengendalian internal. Namun demikian, perlu diperhatikan pula unsur-unsur yang mendukung dalam pengungkapan kelemahanpengendalian internal seperti mempertimbangkan kemungkinan pengendalian kompensasi perlu ditingkatkan kembali.

\section{Hasil Uji Korelasi Spearman Rank}

Correlations

\begin{tabular}{|c|c|c|c|c|}
\hline & & & $\begin{array}{c}\text { Efektivitas } \\
\text { Fungsi } \\
\text { Audit } \\
\text { Internal }\end{array}$ & $\begin{array}{c}\text { Pengungkapan } \\
\text { Kelemahan } \\
\text { Pengendalian } \\
\text { Internal }\end{array}$ \\
\hline \multirow{5}{*}{$\begin{array}{c}\text { Spearman's } \\
\text { rho }\end{array}$} & \multirow[t]{2}{*}{$\begin{array}{l}\text { Efektivitas } \\
\text { Fungsi Audit } \\
\text { Internal }\end{array}$} & $\begin{array}{l}\text { Correlation } \\
\text { Coefficient } \\
\text { Sig. (2- } \\
\text { tailed) }\end{array}$ & 1.000 & $\begin{array}{l}.579 \\
.000\end{array}$ \\
\hline & & $\mathrm{N}$ & 55 & 55 \\
\hline & \multirow{3}{*}{$\begin{array}{l}\text { Pengungkapan } \\
\text { Kelemahan } \\
\text { Pengendalian } \\
\text { Internal }\end{array}$} & $\begin{array}{l}\text { Correlation } \\
\text { Coefficient }\end{array}$ & & 1.000 \\
\hline & & $\begin{array}{l}\text { Sig. }(2- \\
\text { tailed })\end{array}$ & .000 & \\
\hline & & $\mathrm{N}$ & 55 & 55 \\
\hline
\end{tabular}

**. Correlation is significant at the 0.01 level (2-tailed).

Berdasarkan hasil perhitungan diperoleh nilai korelasi Spearman Rank sebesar 0,579 atau $57,9 \%$. Nilai korelasi 0.579 berada dalam rentang nilai antara 0,40 - 0,599 atau tergolong memiliki hubungan yang sedang. Koefisien korelasi 
Spearman rank tersebut mendekati 1 yang menunjukan hubungan yang sedang dan hubungan antara variabel $X$ (Efektivitas Fungsi Audit Internal) terhadap variabel Y (Pengungkapan Kelemahan Pengendalian Internal) menunjukan hubungan positif. Semakin tinggi Efektivitas fungsi audit internal, maka akan semakin meningkatkan Pengungkapan kelemahan pengendalian internal. Dari hasil uji korelasi Spearman Rankmenunjukan bahwa hipotesis yang diajukan peneliti dapat diterima.

\section{Koefisien Determinasi}

$$
\begin{aligned}
& K D=r^{2} \times 100 \% \\
& =(0,579)^{2} \times 100 \\
& =33,5 \%
\end{aligned}
$$

Koefisien determinasi dari hasil perhitungan didapat sebesar 33,5\%. Hal ini menunjukkan bahwa Efektivitas Fungsi Audit Internal memberikan pengaruh sebesar 33,5\% terhadap Pengungkapan Kelemahan Pengendalian Internal, sedangkan sisanya sebesar 66,5\% Pengungkapan Kelemahan Pengendalian Internal dapat dijelaskan oleh variabel lainnya yang tidak diteliti.

\section{Simpulan}

Berdasarkan analisis yang telah peneliti lakukan dan hasil penelitian yang telah peneliti dapatkan pada lima BUMN yang berkantor pusat di Kota Bandung mengenai Pengaruh Efektivitas Fungsi Audit Internal terhadap Pengungkapan Kelemahan Pengendalian Internal, maka dapat disimpulkan bahwa :

1. Efektivitas fungsi audit internal pada BUMN yang berkantor pusat di Kota Bandung berada dalam kategori sangat baik. Dimensi lingkup tugas audit internal memiliki skor yang paling rendah. Hal ini disebabkankarena sumber daya yang dimiliki oleh perusahaan untuk melakukan pengujian sistem manajemen resiko kurang memadai. Dimensi pelaksanaan fungsi audit internal memiliki skor yang paling tinggi. Hal ini disebabkan karena auditor internal selalu melakukan aktivitas pengawasannya secara berkesinambungan sehingga dapat mendorong terciptanya iklim kerja yang efisien

2. Pengungkapan kelemahan pengendalian internal pada BUMN yang berkantor pusat di Kota Bandung berada dalam kategori sangat baik. Dimensi pertimbangan kemungkinan pengendalian kompensasi memiliki skor yang paling rendah. Hal ini disebabkan karena dalam melakukan kaji ulang terhadap prosedur audit internal, perusahaan belum memiliki pedoman yang memadai dan akan berakibat terhadap perusahaan karena dapat menimbulkan kelemahan pengendalian internal sehingga pengendalian internal disebuah perusahaan kurang memadai. Dimensimengidentifikasi pengendalian yang ada memiliki skor yang paling tinggi. Hal ini disebabkan karena auditor internal memperoleh suatu pemahaman dari pengendalian internal sehinggadapat mengumpulkan bukti terkait untuk mendukung penilaian terhadap pengendalian internal perusahaan.

3. Efektivitas fungsi audit internal terhadap pengungkapan kelemahan pengendalian internal pada BUMN yang berkantor pusat di Kota Bandung menunjukan pengaruh yang positif.Berdasarkan hasil penelitian yang telah dilakukan, pengaruh efektivitas fungsi audit internal termasuk dalam kategori sedang, hal ini berarti semakin efektif fungsi audit internal maka akan 334 | Jurnal Riset Akuntansi dan Keuangan Vol.2 | No.2 | 2014 
semakin mendorong pengungkapan kelemahan pengendalian internal yang dijalankan perusahaan.

\section{Saran}

Setelah melakukan penelitian dan memperoleh data-data serta memberikan kesimpulan, peneliti mencoba memberikan saran-saran yang diharapkan dapat lebih meningkatkan efektivitas fungsi audit internal untuk mendorong terciptanya iklim kerja yang efisien. Saran tersebut diantaranya:

a. Badan Usaha Milik Negara (BUMN)

1. Dalam dimensi lingkup tugas audit internal dari variabel efektivitas fungsi audit internal berdasarkan hasil penelitian memiliki skor terendah. Untuk itu, agar dapat meningkatkan sumber daya manusia yang kompeten dalam melakukan pengujian sistem manajemen resiko,para personil audit internal perlu mendapatkan berbagai pelatihan, seminar, dan pendidikan berkelanjutan.

2. Dalam dimensi pertimbangkan kemungkinan pengendalian kompensasi dari variabel pengungkapan kelemahan pengendalian internal berdasarkan hasil penelitian memiliki skor terendah. Untuk itu, para auditor internal perlu melakukan kaji ulang secara berkala untuk mengurangi terjadinya kesalahan manusia berkaitan dengan risiko operasional perusahaan .

3. Banyaknya faktor lain yang mempengaruhi pengungkapan kelemahan pengendalian internalseperti misalnya independensi, ukuran komite audit, dewan komisaris,ukuran perusahaan dan reputasi auditor. Maka dari itu, auditor internal harus bisa mempelajari gejala adanya risiko yang kemungkinan akan terjadi kerugian pada perusahaan.

b. Penelitian Selanjutnya

1. Dalam penelitian ini hanya membahasefektivitas fungsi audit internal terhadap pengungkapan kelemahan pengendalian internal maka pada penelitian selanjutnya diharapkan melakukan penelitian terhadap variabel-variabel lain yang mempengaruhi pengungkapan kelemahan pengendalian internalseperti keahlian akuntansi, independensi, ukuran komite audit, rapat komite audit, dewan komisaris,ukuran perusahaan dan reputasi auditor.

2. Memperbanyak sampel penelitian guna meningkatkan kualitas hasil dari penelitian ini, bukan hanya auditor internal BUMN yang Berpusat di kota Bandung akan tetapi BUMN yang berada di Indonesia.

\section{Daftar Pustaka}

Al-Twaijry, A.A.M., Brierley, J.A. and Gwillian, D.R. 2003,'The Development of Internal Audit in Saudi Arabia: An Institutional Theory Perspective', Critical Perspectives on Accounting, 14:507-351.

Alwi, Hasan, dkk. Kamus Besar Bahasa Indonesia. Jakarta : Balai Pustaka.

Albrecht, W.S., and C.O. Albrecht. 2004. Fraud Examination and Prevention. Mason, Ohio : Thomson/South-Westren.

Arens, et al. 2011.Auditing and Assurance Services: An Integrated Approach. $14^{\text {th }}$ Edition. Pearson Prentice Hall. 
Arens, Alvin A dan Loebbecke, James K. (2004). Auditing Suatu Pendekatan Terpadu. Diterjemahkan oleh Amir Abadi Jusuf. Salemba Empat. Jakarta.

Ashbaugh-Skaife, H., D. Collins, and W. Kinney. 2007. The discovery and reporting of internal control deficiencies prior to SOX-mandated audits. Journal of Accounting and Economics 44 1-2 : 166-192.

Dessalgen Getie Mihret and Aderajew Wondim Yismaw. 2007. Internal Audit effectiveness: An Ethiopian public sector case study. The Auditor Internal. Vol.7 No.2 : Page 470-484.

Fadzil, F.H., Haron, H. \& Jantan, M.(2005), "Internal auditing practices and internal control system", Managerial Auditing Journal, Vol. 20, No. 8,pp. 884-66.20.

Gramling, A. A., M. J. Maletta, A. Schneider, and B. K. Church. 2004. The role of the internal audit function in corporate governance: A synthesis of the extant internal auditing literature and directions for future research. Journal of Accounting Literature 23: 194-244

Husein Umar. (2003). Metode Riset Akuntansi Terapan. Jakarta: Ghalia Indonesia.

Institute of Internal Auditors IIA . 2002. Practice Advisory 1110-2: Chief Audit

Executive (CAE) ReportingLines. Available

at:http://som.csudh.edu/depts/adjunct/mabohebeish/ACC\%20336/

PA\%20ADVISORY/Practice_Advisory_1110-2.pdf.

Jonathan Sarwono. (2010). Pintar Menulis Karya Ilmiah - Kunci Sukses Dalam

Menulis Ilmiah. Yogyakarta: Andi

Konsorsium Organisasi Profesi Audit Internal.(2004). Standar Profesi Audit

Internal. Jakarta: Yayasan Organisasi Profesi Audit Internal.

Mardiasmo. (2004). Akuntansi Sektor Publik. ANDI. Yogyakarta.

Messier, W. F., Jr., and A. Schneider. 1988. A hierarchical approach to the external auditors' evaluation of the internal auditing function. Contemporary Accounting Research 42 : 337-353.

Rezaee, Z. 2002. Forensic accounting practices, education, and certifications.

Journal of Forensic Accounting, 3.2, 207-223

Ridley, J. and D'Silva, K. 1997, 'A Question of Values', Internal Auditor, June:

16-19.

Sawyer, B Lawrence.et al. 2005.Internal Auditing. The IIA: Salemba Empat

Sugiyono. (2010). Metode Penelitian Bisnis. Bandung: Alfabeta.

Sugiyono. (2011). Metode Penelitian Kuantitatif Kualitatif dan R\&D. Bandung: Alfabeta.

Suharsimi Arikunto. (2010). Prosedur Penelitian (Suatu Pendekatan Praktik). Jakarta: RINEKA CIPTA.

Sukrisno Agoes. (2012). Auditing (Pemeriksaan Akuntan oleh Kantor Akuntan

Publik) edisi ketiga. Jakarta: LP-FEUI.

Tugiman, Hiro,(2006). Standar Profesional Audit Internal Edisi Kelima, Yogyakarta: Kanisius

Van Gansberghe, C.N. (2005), "Internal auditing in the public sector: a consultative forum in Nairobi, Kenya, shores up best practices for government audit professionals in developing nations", Internal Auditor, Vol. 62, No. 4, pp. 69-73. 
Zhang, Yang. Zhou, J.dan Zhou, N. 2007. Audit Committee quality, auditor independence, and internal control weaknesses. Journal of Accounting and Public Policy. 26 300-32

- 2004. Internal Auditing's Role in Sections 302 and 404 of the SarbanesOxley Act. Available at: http://www.theiia.org/iia/download.cfm?file 1655. . 2008. International Standards for the Professional Practice of Internal Auditing. Available at: http:// www.theiia.org/guidance/standards-andguidance/ippf/standards/.

(2011). Peraturan Menteri Negara Badan Usaha Milik Negara Nomor : PER-01/MBU/2011 Tentang Penerapan Tata Kelola Perusahaan yang Baik(Good Corporate Governance) Pada Badan Usaha Milik Negara (2012).Salinan Keputusan Sekretaris Kementerian Badan Usaha Milik Negara Nomor: SK-16/S.MBU/2012 Tentang Indikator/Parameter Penilaian dan Evaluasi atas Penerapan Tata Kelola Perusahaan yang Baik (Good Corporate Governance) pada Badan Usaha Milik Negara.

http://www.bumn.go.id

http://www.theiia.org

http://www.telkom.co.id 